\title{
Laser Flash Photolysis Study of the Phenolic Hydrogen Abstraction by 1,2-Aceanthrylenedione Triplet
}

\author{
Ana Cristina S. Serra ${ }^{a}$, Nanci C. de Lucas ${ }^{a}$ and José Carlos Netto-Ferreira ${ }^{*, b}$ \\ ${ }^{a}$ Instituto de Química, Universidade Federal do Rio de Janeiro, Cidade Universitária, Ilha do Fundão, CT, Bloco A, \\ 21949-970 Rio de Janeiro - RJ, Brazil \\ ${ }^{b}$ Departamento de Química, Universidade Federal Rural do Rio de Janeiro, Antiga Rio-São Paulo km 47, \\ 23851-970 Seropédica - RJ, Brazil
}

\begin{abstract}
A técnica de fotólise por pulso de laser de nanossegundo foi empregada no estudo da reatividade do triplete de 1,2-aceantrilenodiona (1) frente a fenóis. As constantes de velocidade de supressão $\left(\mathrm{k}_{\mathrm{q}}\right)$, em acetonitrila, variaram de $3,3 \times 10^{5} \mathrm{~L} \mathrm{~mol}^{-1} \mathrm{~s}^{-1}$ (fenol) a $1,3 \times 10^{7} \mathrm{~L} \mathrm{~mol}^{-1} \mathrm{~s}^{-1}$ (4-hidroxifenol), com os fenóis contendo substituintes doadores de elétrons mostrando-se mais reativos. O efeito isotópico cinético $\left(\mathrm{k}_{\mathrm{H}} / \mathrm{k}_{\mathrm{D}}\right)$ observado para a supressão de 1 por 4-metoxifenol foi de 1,5. O gráfico de Hammett para a reação do triplete de $\mathbf{1}$ com fenóis forneceu uma constante de reação $\rho=-1,04$, em acetonitrila. $\mathrm{O}$ baixo valor encontrado para a constante de velocidade de supressão deste triplete com 1,3-cicloexadieno $\left(\mathrm{k}_{\mathrm{q}}=2,0 \times 10^{4} \mathrm{~L} \mathrm{~mol}^{-1} \mathrm{~s}^{-1}\right)$, assim como o fato de que a constante de velocidade de supressão por $\beta$-caroteno é controlada por difusão, sugerem que a energia do triplete de energia mais baixa para 1,2-aceantrilenodiona situa-se entre 88 e $219 \mathrm{~kJ} \mathrm{~mol}^{-1}$.
\end{abstract}

The nanosecond laser flash photolysis technique has been used to study the reactivity of 1,2aceanthrylenedione (1) triplet towards phenols. Using acetonitrile as solvent, the quenching rate constant $\mathrm{k}_{\mathrm{q}}$ ranged from $3.3 \times 10^{5} \mathrm{~L} \mathrm{~mol}^{-1} \mathrm{~s}^{-1}$ (phenol) to $1.3 \times 10^{7} \mathrm{~L} \mathrm{~mol}^{-1} \mathrm{~s}^{-1}$ (4-hydroxyphenol). Phenols with electron donating substituents were more reactive. The kinetic isotope effect $\left(\mathrm{k}_{\mathrm{H}} / \mathrm{k}_{\mathrm{D}}\right)$ observed for the quenching of $\mathbf{1}$ with 4-methoxyphenol was 1.5. The Hammett plot for the reaction of the triplet of 1 with phenols gave a reaction constant $\rho=-1.04$ in acetonitrile solution. The low value for the quenching rate constant measured for this triplet with 1,3 -cyclohexadiene $\left(\mathrm{k}_{\mathrm{q}}=2.0 \times 10^{4} \mathrm{~L}\right.$ $\mathrm{mol}^{-1} \mathrm{~s}^{-1}$ ) and the diffusion controlled quenching rate constant obtained for $\beta$-carotene suggest that the energy of the lowest triplet state for 1,2-aceanthrylenedione is located between 88 and $219 \mathrm{~kJ} \mathrm{~mol}^{-1}$.

Keywords: laser flash photolysis, diketones, hydrogen abstraction, triplet state

\section{Introduction}

Hydrogen atom abstraction rate constants from the triplet state of $\alpha$-diketones are extremely dependent on their chemical structure. Biacetyl, having a low-lying $n \pi^{*}$ triplet state, shows hydrogen abstraction rate constants ranging from $3.0 \times 10^{3} \mathrm{~L} \mathrm{~mol}^{-1} \mathrm{~s}^{-1}$ (2-propanol) to $3.4 \times 10^{8} \mathrm{~L} \mathrm{~mol}^{-1} \mathrm{~s}^{-1}$ (phenol). ${ }^{1}$ On the other hand, $1,1,4,4-$ tetramethyl-1,4-dihydro-2,3-naphthalendione, which has also a low lying $\mathrm{n} \pi^{*}$ triplet state, shows remarkably fast hydrogen abstraction rate constants. ${ }^{2}$ Despite its low triplet energy $\left(E_{\mathrm{T}}=230 \mathrm{~kJ} \mathrm{~mol}^{-1}\right)^{2}$ the reaction rate constant for the latter diketone in the presence of hydrogen donor exceeds that of triplet benzophenone. ${ }^{3}$ Large hydrogen abstraction rate constants were also found for

* e-mail: jcnetto@ufrrj.br acenaphthenequinone, for which rate constant values ranging from $6.2 \times 10^{5} \mathrm{~L} \mathrm{~mol}^{-1} \mathrm{~s}^{-1}$ (2-propanol) to $3.1 \times 10^{9} \mathrm{~L}$ $\mathrm{mol}^{-1} \mathrm{~s}^{-1}$ (4-methoxyphenol) were measured by the laser flash photolysis technique. ${ }^{4}$ The surprisingly high reactivity for the triplet of cisoid diketones such as 1,1,4,4tetramethyl-1,4-dihydro-2,3-naphthalendione and acenaphthenequinone towards hydrogen donors has been attributed to a considerable degree of stabilization of the resulting ketyl radical formed by hydrogen abstraction from their triplet state. This extra stabilization occurs through intramolecular hydrogen bonding between the hydroxyl group and its vicinal carbonyl. ${ }^{2}$

Ketones having a low energy triplet state with $\pi \pi^{*}$ character are much less reactive towards aliphatic or benzylic hydrogen abstraction than those with $n \pi^{*}$ character. ${ }^{5}$ Thus, examples of $\pi \pi^{*}$ ketones for which hydrogen abstraction rate constants could be measured, such as 1,1'-, 1,2'- and 
2,2'-dinaphthyl ketones, ${ }^{6}$ reveal that these rate constants are much slower $\left(\mathrm{k}_{\mathrm{q}} \bullet 10^{5} \mathrm{~L} \mathrm{~mol}^{-1} \mathrm{~s}^{-1}\right.$ for 1,4-cyclohexadiene) than those observed for $\mathrm{n} \pi *$ ketones. Besides this, $\pi \pi^{*}$ triplets are known to be unreactive in the presence of alcohols ( $\mathrm{k}_{\mathrm{q}}<<10^{5} \mathrm{~L} \mathrm{~mol}^{-1} \mathrm{~s}^{-1}$ for 2-propanol). ${ }^{6}$ The $\alpha$-dicarbonyl compounds 1,2-naphthalenedione and 9,10-phenanthrenequinone show triplet reactivity, which is dependent on the solvent polarity. ${ }^{7}$ This can be explained by an inversion of their $\mathrm{n} \pi^{*}$ and $\pi \pi^{*}$ triplet states which are relatively close in energy. Thus, in nonpolar solvents, these two diketones show a triplet state of lowest energy with $\pi \pi^{*}$ character, whereas in polar solvents the triplet state has $n \pi^{*}$ character. On the other hand, the triplet state of 1,2-aceanthrylenedione (1) is insensitive to the solvent polarity, showing $\pi \pi^{*}$ character in both polar and nonpolar solvents, and being unreactive towards alcohols, ethers and hydrocarbons. However, $\mathbf{1}$ is efficiently reduced by electron donors such as triethylamine $\left(\mathrm{k}_{\mathrm{q}}=3.4 \times 10^{6} \mathrm{~L} \mathrm{~mol}^{-1} \mathrm{~s}^{-1}\right.$, in $\left.\mathrm{ACN}\right)$ and 1,4-diazabicyclo [2.2.2] octane (DABCO) $\left(\mathrm{k}_{\mathrm{q}}=3.7 \times 10^{9} \mathrm{~L} \mathrm{~mol}^{-1} \mathrm{~s}^{-1}\right.$, in $\left.\mathrm{ACN}\right){ }^{7}$

From above, it is clear that $\mathbf{1}$ is unreactive towards poor hydrogen donors such as alcohols, ethers and hydrocarbons. However, nothing is known about its triplet reactivity towards better hydrogen donors such as phenols. Hydrogen abstraction from phenols by the triplet state of aromatic ketones is a fast process, close to the diffusioncontrolled rate, and results in the reversible formation of the phenoxyl-ketyl radical pair. ${ }^{8}$ Unlike the reaction with the poor hydrogen donors cited above, the hydrogen abstraction from phenols is independent of the character of the lowest triplet state of the ketone. Thus, it is not uncommon that $\pi \pi^{*}$ triplet state ketones react faster towards phenols than those with $n \pi^{*}$ character. $^{8}$ This behavior suggests that the quenching process of a carbonyl triplet by phenols is different from those in which a $\mathrm{C}-\mathrm{H}$ bond is being broken, as for hydrocarbons and alcohols. In the latter case the reaction occurs by a hydrogen atomtransfer mechanism, whereas, in the former, the mechanism passes through a hydrogen-bonded complex and involvement of the relatively basic $\pi \pi^{*}$ triplet state has been suggested. ${ }^{9}$

In this work we report the results of a systematic study of the reactivity of 1,2-aceanthrylenedione (1) in the presence of substituted phenols employing the laser flash photolysis technique.

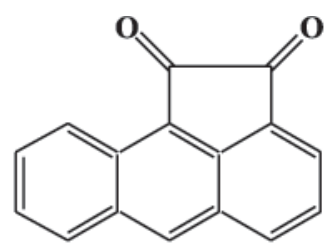

\section{Experimental}

\section{Materials}

The solvents, acetonitrile, benzene, dichloromethane, methanol, iso-propanol (VETEC spectrograde) and deuterium oxide were used as received. Phenol, 3methoxyphenol, 4-methoxyphenol, 4-tert-butylphenol, 4hydroxyphenol, 4-phenylphenol, 4-chlorophenol and 4bromophenol, from Aldrich, were used as received (purity $>99 \%$ ).

Acetonitrile used for the isotope effect study (OmniSolv Spectrograde), from a recently opened bottle, was not dried before use. Deuterium oxide (Matheson, Coleman and Bell, $99,5 \%)$ was used as received.

1,2-aceanthrylenedione (Aldrich) was recrystallized from ethanol, $\mathrm{mp}=249-250{ }^{\circ} \mathrm{C}\left(\right.$ Lit. $\left.^{10} \mathrm{mp}=251^{\circ} \mathrm{C}\right)$.

\section{Laser flash photolysis}

The laser flash photolysis (LFP) experiments were carried out on Edinburgh Analytical Instruments LP900, which has been previously described. ${ }^{4}$ Samples were contained in a $10 \mathrm{~mm} \times 10 \mathrm{~mm}$ cell made from Pyrex tubing and were deaerated by bubbling with oxygen-free nitrogen for about $30 \mathrm{~min}$. Two syringe needles, one for bubbling the nitrogen ( $20 \mathrm{~cm}$ long) and the other to act as a vent ( 3 $\mathrm{cm}$ long), were inserted into the cell through a tight septum. Removal of the needles, vent first, left a slight over-pressure of nitrogen inside the cell.

The samples were irradiated with a Nd/YAG Surelite laser, using the third harmonic $(\lambda=355 \mathrm{~nm}, \sim 4$ to $6 \mathrm{~ns}, \mathrm{t} 40$ $\mathrm{mJ} /$ pulse), with the signal being detected by a Tektronix TDS520 oscilloscope.

The 1,2-aceanthrylenedione concentration $\left(\sim 1 \mathrm{mmol} \mathrm{L}^{-1}\right)$ was chosen in order to give an absorption in the wavelength of excitation (355 nm) of 0.3-0.5. Stock solutions of quenchers were prepared so that it was only necessary to add microliter volumes to the sample cell in order to obtain appropriate concentrations of the quencher.

\section{Results}

Laser irradiation of a degassed solution of 1,2aceanthrylenedione (1) in acetonitrile resulted in the formation of a signal with maximum at $465 \mathrm{~nm}$ and a large absorption in the 600-680 $\mathrm{nm}$ range, showing a lifetime of $15 \mu \mathrm{s}$, which did not change with the solvent polarity. Thus, values around $15 \mu$ s were also obtained in benzene, dichloromethane and methanol as solvent. This transient, having $\pi \pi^{*}$ configuration, has been previously 
characterized as the triplet state of $\mathbf{1} .^{7}$ The triplet nature of this species was further confirmed in the present work by quenching with $\beta$-carotene $\left(\mathrm{E}_{\mathrm{T}}=88 \mathrm{~kJ} \mathrm{~mol}^{-1}\right){ }^{11}$ for which we obtained a diffusion controlled quenching rate constant, with the concomitant formation of the $\beta$-carotene triplet at $\lambda_{\max }=535 \mathrm{~nm}$. Figure 1 shows the triplet-triplet absorption spectrum for $\beta$-carotene, whereas the insert for this figure displays the growth and decay for this transient. For 1,3-cyclohexadiene $\left(\mathrm{E}_{\mathrm{T}}=219 \mathrm{~kJ} \mathrm{~mol}^{-1}\right)^{11}$ we measured a quenching rate constant of $(2.0 \pm 0.1) \times 10^{4} \mathrm{~L} \mathrm{~mol}^{-1} \mathrm{~s}^{-1}$, which is far below the diffusion control limit, a value expected for an endothermic energy transfer process. From these quenching experiments we can estimate that the triplet energy of $\mathbf{1}$ has limits between 88 and $219 \mathrm{~kJ} \mathrm{~mol}^{-1}$, which is in full agreement with a triplet state localized on the anthracene moiety $\left(\mathrm{E}_{\mathrm{T}}=178 \mathrm{~kJ} \mathrm{~mol}^{-1}\right) \cdot{ }^{11}$ Addition of hydrogen donors, such as phenols, led to a shortening of the triplet lifetime of $\mathbf{1}$ with the triplet decay following pseudo-first order kinetics in the presence of these quenchers.

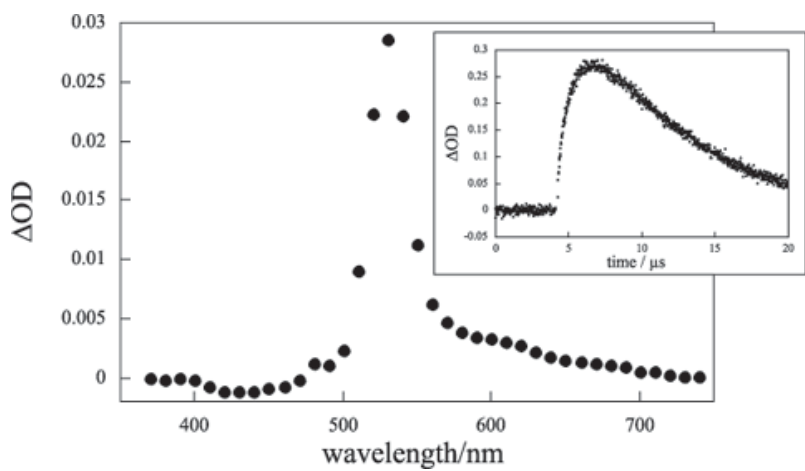

Figure 1. Triplet-triplet absorption spectrum for $\beta$-carotene obtained from energy transfer from 1,2-aceanthrylenedione triplet in acetonitrile. Insert: Growth and decay of the $\beta$-carotene triplet.

The experimentally observed pseudo-first-order kinetic rate constant, $\mathrm{k}_{\mathrm{obs}}$, is related to the quenching rate constant, $\mathrm{k}_{\mathrm{q}}$, according to equation 1 .

$\mathrm{k}_{\mathrm{obs}}=\mathrm{k}_{0}+\mathrm{k}_{\mathrm{q}}[\mathrm{Q}]$

where $\mathrm{k}_{0}$ is the decay rate constant of the triplet in the absence of the quencher, and [Q] the quencher concentration.

Plots based on this equation for the triplet of $\mathbf{1}$ being quenched by various phenols were found to be linear, from which one can determine the value of $\mathrm{k}_{\mathrm{q}}$. Figure 2 shows representative plots for the quenching of $\mathbf{1}$ by several phenols, whereas the Table 1 shows the rate constants obtained from these plots, in acetonitrile. This table also contains the quenching rate constant obtained in benzene solution for 4-methoxyphenol.

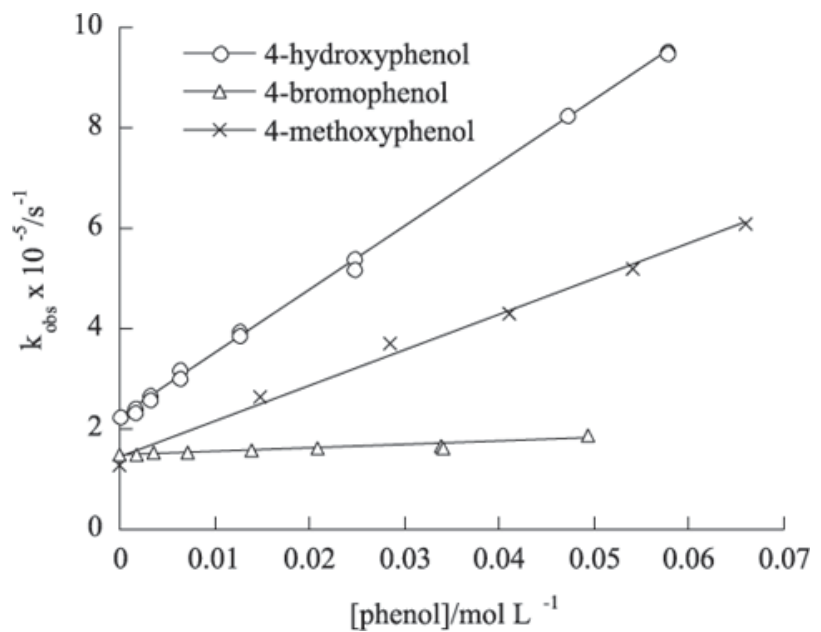

Figure 2. Representative quenching plots of 1,2-aceanthrylenedione triplet by several phenols in acetonitrile.

Table 1. Second order rate constants for the quenching of the triplet of $\mathbf{1}$ by various phenols in acetonitrile

\begin{tabular}{ll}
\hline Quencher & $\mathrm{k}_{\mathrm{q}} / \mathrm{L} \mathrm{mol}^{-1} \mathrm{~s}^{-1}$ \\
\hline 4-hydroxyphenol & $(1.2 \pm 0.1) \times 10^{7}$ \\
4-methoxyphenol & $(7.0 \pm 0.4) \times 10^{6}$ \\
& $(6.6 \pm 0.5) \times 10^{7 \mathrm{a}}$ \\
3-methoxyphenol & $(2.7 \pm 0.2) \times 10^{6}$ \\
4-chlorophenol & $(1.6 \pm 0.1) \times 10^{6}$ \\
4-terc-butylphenol & $(1.4 \pm 0.1) \times 10^{6}$ \\
4-phenylphenol & $(1.1 \pm 0.1) \times 10^{6}$ \\
4-cyanophenol & $(2.1 \pm 0.2) \times 10^{5}$ \\
4-bromophenol & $(6.9 \pm 0.5) \times 10^{5}$ \\
phenol & $(3.3 \pm 0.2) \times 10^{5}$ \\
\hline
\end{tabular}

${ }^{\text {aIn }}$ benzene.

Figure 3 shows the transient spectrum recorded after excitation of 1 with (A) and without (B) 4-methoxyphenol. Concomitant to a sharp decrease of the triplet-triplet absorption of 1, a new band with maximum at $410 \mathrm{~nm}$ was observed in the presence of this phenol, which can be associated with the 4-methoxyphenoxyl radical. ${ }^{12}$ Furthermore, the absorption maxima at 550 and $590 \mathrm{~nm}$ can be associated with the ketyl radical 2 (or 3 ) derived from 1,2-aceanthrylenedione.

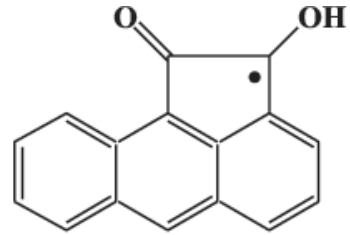

2<smiles></smiles>

3
The corresponding anion-radical 4 was not considered as a candidate for the transient with absorption maxima at 
550 and $590 \mathrm{~nm}$ since a proton transfer from the phenol cation-radical to $\mathbf{4}$ must rapidly follow its formation, resulting in the corresponding ketyl-phenoxyl radical pair. ${ }^{8}$

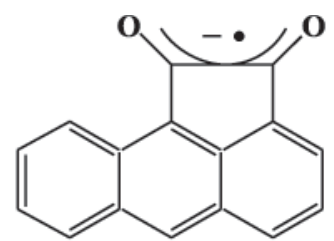

4

The quenching rate constant for the triplet of $\mathbf{1}$ with the well-known hydrogen donors 1,4-cyclohexadiene and 2-propanol was extremely low and estimated to be $<10^{4} \mathrm{~L} \mathrm{~mol}^{-1} \mathrm{~s}^{-1}$.
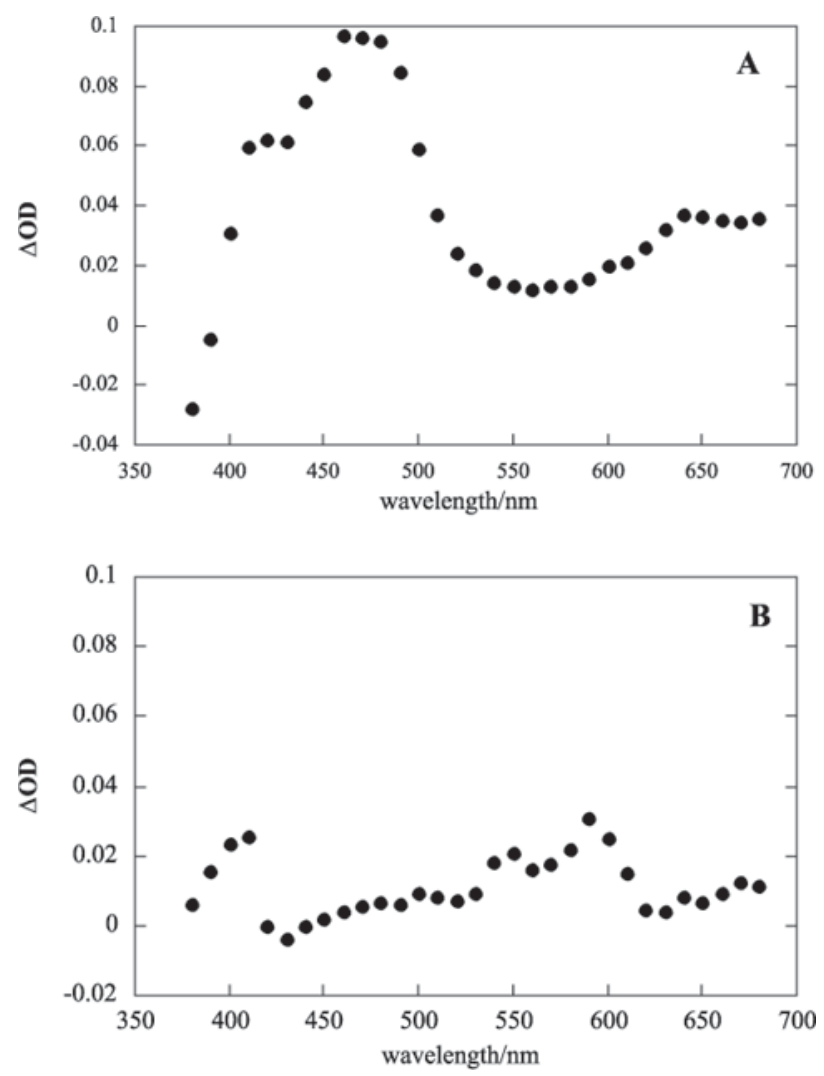

Figure 3. (A) Triplet-triplet absorption spectrum for 1,2aceanthrylenedione (1), in acetonitrile. (B) Transient absorption spectrum obtained after excitation of $\mathbf{1}$ in the presence of $0.14 \mathrm{~mol}$ $\mathrm{L}^{-1} 4$-methoxyphenol in acetonitrile solution.

The behavior of the triplet of $\mathbf{1}$ in the presence of 4methoxyphenol was examined in 9:1 acetonitrile-water and in 9:1 acetonitrile- $\mathrm{D}_{2} \mathrm{O}$, from which one could obtain rate constants of $(4.5 \pm 0.2) \times 10^{7} \mathrm{~L} \mathrm{~mol}^{-1} \mathrm{~s}^{-1}$ and $(3.0 \pm 0.2) \times 10^{7}$ $\mathrm{L} \mathrm{mol}^{-1} \mathrm{~s}^{-1}$, respectively (Figure 4).

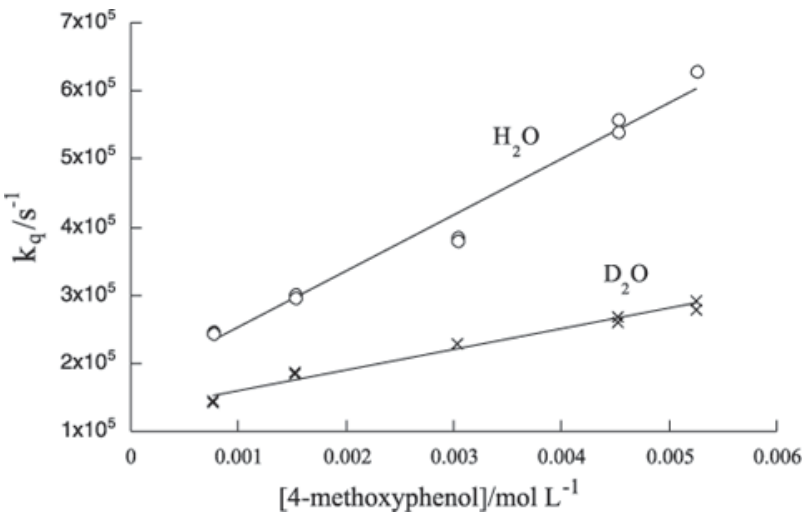

Figure 4. Quenching plots of 1,2-aceanthrylenedione (1) by 4methoxyphenol in ACN: $\mathrm{H}_{2} \mathrm{O}(\mathrm{o})$ and in $\mathrm{ACN}: \mathrm{D}_{2} \mathrm{O}(\mathrm{x})$.

\section{Discussion}

It has been observed that the reactivity for the 1,2aceanthrylenedione triplet towards 4-methoxyphenol and phenol is around 2 to 3 orders of magnitude smaller than the reactivity of monoketone triplets with $n \pi *$ configuration. ${ }^{13}$ It is worth noting that the observed hydrogen abstraction rate constants for phenols is 2 orders of magnitude slower than for other $\pi \pi^{*}$ ketones such as para-methoxypropiophenone. ${ }^{8}$ This difference in reactivity is probably due to differences in the $\Delta H$ of the reaction, reflecting the lower triplet energy of 1,2aceanthrylenedione. ${ }^{4}$

Among all the phenols analyzed, 4-hydroxyphenol and 4-methoxyphenol were those that showed larger quenching rate constants. The absorption spectrum of $\mathbf{1}$ in the presence of these phenols clearly show the appearance of a peak with maximum around $410 \mathrm{~nm}$ (Figure 2). This absorption was attributed to the corresponding phenoxyl radicals, as they have a strong absorption in the $370-505 \mathrm{~nm}$ region, which depends upon ring substituents. ${ }^{12}$

It was observed that in benzene the quenching rate constant for the triplet of $\mathbf{1}$ with 4-methoxyphenol was larger than in acetonitrile solution (Table 1). This observation is in agreement with previous results in the literature, which indicate that the reactivity of carbonyl triplets in hydrogen abstraction reactions from phenols is strongly reduced in polar solvents. ${ }^{1,8,12}$ This difference in reactivity between polar and non-polar solvents was attributed to the higher concentration of free reactive phenol in the latter. ${ }^{4,7,14}$ However, this has been contested due to the fact that the difference in reactivity between two given solvents is strongly dependent on structure of the ketone employed. ${ }^{6}$

For the quenching with typical hydrogen donors such as 1,4-cyclohexadiene and iso-propanol, a value for the 
quenching rate constants was estimated to be $<10^{4} \mathrm{~L} \mathrm{~mol}^{-1} \mathrm{~s}^{-1}$, which is considerably lower than for phenols. These quenching rate constants are also slower than those for mono and diketones with an $n \pi *$ configuration. The quenching rate constants for the triplet of $\mathbf{1}$ obtained with these typical hydrogen donors reinforce the low reactivity of the triplet state of aromatic carbonyl compounds with a $\pi \pi^{*}$ configuration relative to hydrocarbons and alcohols. ${ }^{14,15}$ The larger hydrogen abstraction rate constant by phenol, compared to that for 1,4-cyclohexadiene and iso-propanol, is in agreement with a mechanism involving an initial charge transfer process (Scheme 1). Furthermore, the absence of a solvent effect on the triplet lifetime of $\mathbf{1}$ indicates that the energy gap $\pi \pi^{*}-\mathrm{n} \pi^{*}$ in this case is much higher than that observed for other 1,2-diones, such as 1,2-naphthalenedione, acenaphthenequinone or 9,10-phenanthrenequinone. ${ }^{7}$ However, it seems that the so-called lack of reactivity of $\pi \pi *$ ketones towards hydrogen abstraction is not a general case, and depends on the mechanism involved.

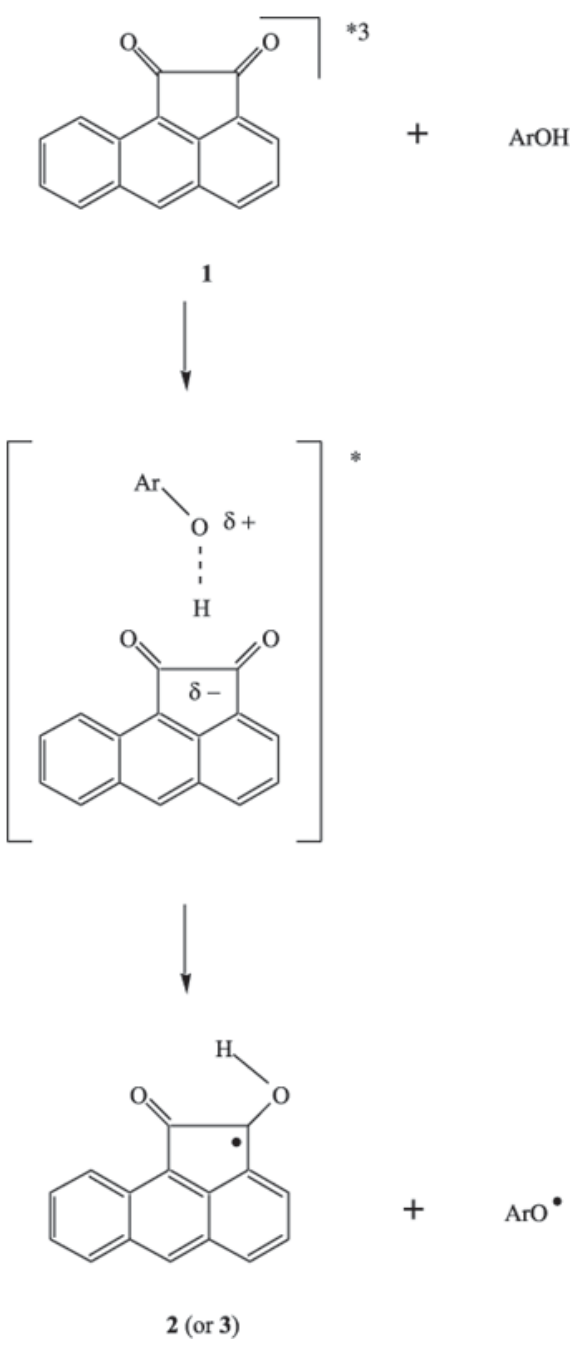

Scheme 1.
A clear indication that the energy for the triplet excited state of 1,2-aceanthrylenedione is less than $219 \mathrm{~kJ} \mathrm{~mol}^{-1}$ was found by the quenching of the 1,2aceanthrylenedione triplet by 1,3-cyclohexadiene $\left(\mathrm{E}_{\mathrm{T}}=\right.$ $\left.219 \mathrm{~kJ} \mathrm{~mol}^{-1}\right)$ where $\mathrm{k}_{\mathrm{q}}=(1.9 \pm 0.1) \times 10^{4} \mathrm{~L} \mathrm{~mol}^{-1} \mathrm{~s}^{-1}$, a rate constant much slower than that expected for an energy transfer process. If one compares this value with the reported triplet energy of anthracene $\left(\mathrm{E}_{\mathrm{T}}=178 \mathrm{~kJ} \mathrm{~mol}^{-1}\right)$, we can conclude that the excitation of $\mathbf{1}$ is located on the anthracene moiety.

The Hammett plot for the quenching rate constants for the reaction of $\mathbf{1}$ with substituted phenols against $\sigma+$ (Figure 5) gave a reaction constant $\rho$ of $-1.04 \pm 0.22$. This indicates that, despite the poor correlation $(\mathrm{r}=0.84)$ observed in this plot, the transition state of $\mathbf{1}$ presents some eletrophilic character, which is in agreement with the known behavior of carbonyl triplets towards abstraction of phenolic hydrogen. ${ }^{16}$ By comparison, the value obtained by Lucas et al. for the reaction of acenaphthenequinone, a $\alpha$-diketone with $\mathrm{n} \pi^{*}$ configuration, with phenols ( $\rho=$ $-1.50 \pm 0.17),{ }^{4}$ clearly reveals that the eletrophilic character of $\mathbf{1}$ is less than that of acenaphthenequinone. As stated above, the larger hydrogen abstraction rate constants for phenols than for 1,4-cyclohexadiene and iso-propanol is a clear indication that the mechanism for hydrogen abstraction in the later examples does not involve an initial charge transfer interaction.

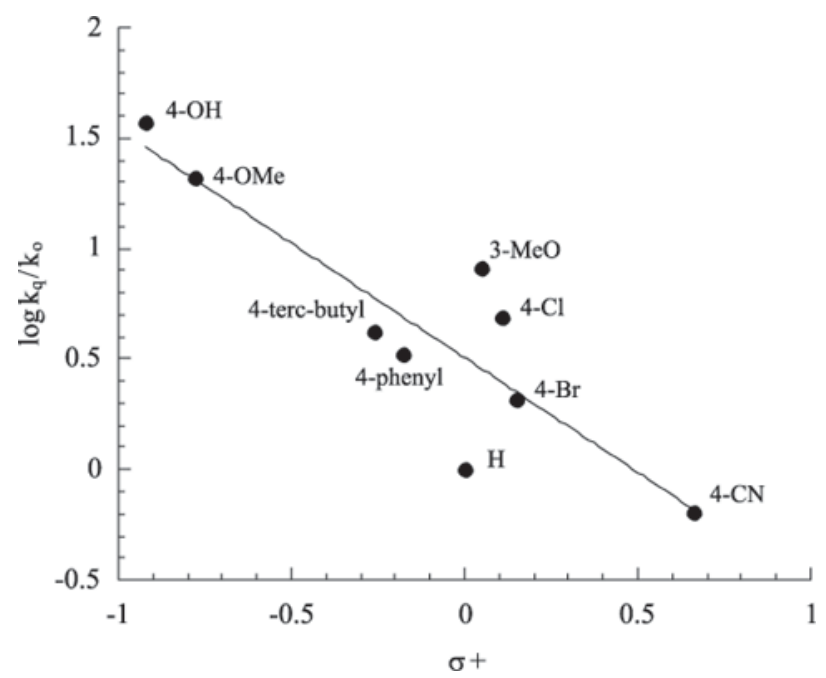

Figure 5. Hammett plot for the hydrogen abstraction of the triplet of 1 by phenols, in acetonitrile.

The deuterium isotope effect observed for the reaction of the triplet of 1 with 4-methoxyphenol was $\left(\mathrm{k}_{\mathrm{H}} / \mathrm{k}_{\mathrm{D}}=1.5\right)$ (Figure 4). This value is sufficiently close to that observed for the hydrogen transfer from phenols to acenaphthenequinone $\left(\mathrm{k}_{\mathrm{H}} / \mathrm{k}_{\mathrm{D}}=1.3\right)^{4}$ and benzophenone $\left(\mathrm{k}_{\mathrm{H}} / \mathrm{k}_{\mathrm{D}}=1.2\right) .{ }^{17}$ 
As suggested earlier by Lucas et al., ${ }^{4}$ the $\mathrm{O}-\mathrm{H}$ bond stretching in the transition state must be less important for diketones than for monoketones. In this case, the vicinal carbonyl could assist in the hydrogen abstraction reaction leading to a more organized transition state. This argument can be used to explain the difference in the deuterium isotope effect observed between the diketone $\mathbf{1}$ and paramethoxypropiophenone $\left(\mathrm{k}_{\mathrm{H}} / \mathrm{k}_{\mathrm{D}}=1.9\right),{ }^{15}$ both of which have $\pi \pi^{*}$ character.

\section{Conclusions}

In conclusion, it was shown that the triplet energy of 1,2-aceanthrylenedione (1) has a value below $219 \mathrm{~kJ} \mathrm{~mol}^{-1}$, and that its energy excitation is located on the anthracene moiety. Despite the fact that the triplet excited state of lowest energy for $\mathbf{1}$ has a $\pi \pi^{*}$ character, it is able to abstract a hydrogen atom from phenols, with quenching rate constants ranging from $3.3 \times 10^{3} \mathrm{~L} \mathrm{~mol}^{-1} \mathrm{~s}^{-1}$ (for 4-cyanophenol) to $1.2 \times 10^{7} \mathrm{~L} \mathrm{~mol}^{-1} \mathrm{~s}^{-1}$ (4-hydroxyphenol). Furthermore, phenolic hydrogen abstraction by the triplet of $\mathbf{1}$ is faster than for 1,4-cyclohexadiene and iso-propanol. This led us to conclude that the mechanism for phenolic hydrogen abstraction involves a partial charge transfer process, which was confirmed by the reaction constant $(\rho=-1.04 \pm 0.22)$ obtained from a Hammett plot for the quenching rate constants of $\mathbf{1}$ by several phenols.

\section{Acknowledgements}

This work has been supported by the Conselho Nacional de Desenvolvimento Científico e Tecnológico (CNPq-Brazil) and Fundação Carlos Chagas Filho de Amparo à Pesquisa do Estado do Rio de Janeiro (FAPERJ). JCN-F thanks CNPq-Brazil for a research fellowship.

\section{References}

1. Turro, N. J.; Engel, R.; J. Am. Chem. Soc. 1969, 91, 7113.

2. Scaiano, J. C.; Wintgens, V.; Netto-Ferreira, J. C.; Photochem. Photobiol. 1989, 50, 707.

3. Scaiano, J. C.; Becknell, A. F.; Small, R. D.; J. Photochem. Photobiol A: Chem. 1988, 44, 4396.

4. Lucas, N. C.; Netto-Ferreira, J. C.; J. Photochem. Photobiol. A: Chem. 1998, 116, 203.

5. Gilbert, A.; Baggot, J.; Essentials of Molecular Photochemistry, Blackwell Science Ltd.: Oxford, 1991.

6. Jovanovic, S. V.; Morris, D. G.; Pliva, C. N.; Scaiano, J. C.; J. Photochem. Photobiol. A: Chem. 1997, 107, 153.

7. Barra, M.; Harder, E. D.; Balfe, J. P.; J. Chem. Soc., Perkin Trans II 1999, 1439.

8. Das, P. K.; Encinas, M. V.; Scaiano, J. C.; J. Am. Chem. Soc. 1981, 103, 4154.

9. Lathioor, E. C. ; Leigh, W. L.; Can. J. Chem. 2001, 79, 1851.

10. Stetcher, P. G.; Rahway, N. J.; Merck, N. J.; The Merck Index, an Encyclopedia of Chemical, Drugs, and Biologicals, Merck Research Laboratories: New Jersey, 1996.

11. Murov, S. L.; Carmichael, I.; Hug, G. L.; Handbook of Photochemistry, Marcel Dekker, Inc.: New York, 1993.

12. Das, P. K.; Encinas, M. V.; Steenken, S.; Scaiano, J. C.; J. Am. Chem. Soc. 1981, 103, 4162.

13. Turro, N. J.; Modern Molecular Photochemistry, University Science Books: Mill Valley, CA, 1991.

14. Wagner, P.; Park, B.-S.; Org. Photochem. 1991, 2, 227.

15. Leigh, W. J.; Lathioor, E. C.; Pierre, M. J. S.; J. Am. Chem. Soc. 1996, 118, 12339.

16. Wagner, P. J.; Zepp, R. G.; Liu, K.-C.; Thomas, M.; Lee, T.-J.; Turro, N. J.; J. Am. Chem. Soc. 1976, 98, 8125.

17. Scaiano, J. C.; J. Photochem. 1974, 2, 81.

Received: August 1, 2003

Published on the web: May 17, 2004 